\title{
The current state of quality management in human resources evaluation process in Romania public higher education system
}

\author{
Muscalu Emanoil ${ }^{1,2}$, Stanit Alexandra ${ }^{1,2,{ }^{*}, \text { Constantinescu Mihaela Liliana }}{ }^{1,2}$ \\ ${ }^{1}$ Dep. of Management, Marketing and Business Administration, Sibiu, Romania \\ ${ }^{2}$ Lucian Blaga" University of Sibiu, Sibiu, Romania

\section{Email address:} \\ emanoil.muscalu@ulbsibiu.ro (E. Muscalu), alexandra.stanit@ulbsibiu.ro (A. Stăniț), lili.popa@ulbsibiu.ro (L.M. Constantinescu)
}

\section{To cite this article:}

Muscalu Emanoil, Stanit Alexandra, Constantinescu Mihaela Liliana. The Current State of Quality Management in Human Resources Evaluation Process in Romania Public Higher Education System. Journal of Human Resource Management.

Vol. 2, No. 2, 2014, pp. 42-46. doi: 10.11648/j.jhrm.20140202.12

\begin{abstract}
HR resources are essential elements for the development and successful operation of contemporary higher education systems. Knowledge, skills, attitudes, motivation, individual characteristics of the university's employees are the ones that provide the foundation for achieving quality. Changes in economic, social, demographic and technological sectors generate a dynamic external environment and sometimes difficult to predict. To understand the importance of the human resources evaluation process in universities, we must have in mind that this is a basic component of human resource management and quality management. Viewed as a way to get individual and organizational results much better by understanding and managing performance within a unified framework and context of learning, quality management can be defined as a strategic and integrated approach to ensure lasting success in universities activities.
\end{abstract}

Keywords: Quality, Human Resource, Evaluation, Public Higher Education System

\section{Introduction}

The overall picture of our higher education quality status, as it arises from academics, students and employers perceptions, is a high quality one. But when we focus on the system results, the resulting image is, in large part, the one of a self-focused one. It is rather the perception of the system whose links are insufficiently explored and analyzed, following their own logic system, coherent, but is less involved in society and rather disconnected from it.

Thus, students, teachers and employers continue to have a positive overview on the state of the higher education quality system. Only that, this positive higher education quality system is doubled by the lack of confidence declining trends in universities, especially regarding their link with the labor market. This apparent paradox between valuing positive overall image quality and lack of confidence about the ability of universities to achieve certain ends can be explained by ambiguity regarding the social functions of the university. We are still in a society where universities are seen as an instance of general, academic, to whose services should have access only the best, whose main purpose is to prepare elite.

Another tension about the quality of the system derives from the overall perception of its ability to prepare graduates for labor market. Employers take a relatively neutral position; there is also a large gap between the current level of graduates skills and employers demands. The image of two types of actors contrast, the academics being more positive than the employers [5]. Solving this tension is fundamental to social engagement of higher education system, which otherwise risks losing contact with the labor market and cause significant damage to its image in the future. On the other hand, should not be neglected that the labor market is not structured and the current crisis has deepened uncertainty regarding future developments of the labor market. So, no national program for long-term development can guide universities to establish their strategies. 


\section{Peculiarities of the Human Resources Evaluation Process in Universities}

\subsection{Managing and Developing Human Resources in the University Systems}

Human resources are the creative, active and coordinating element within organizations activities, decisively influencing the efficacy of using material, financial and informational resources. Human resource management requires high levels of genuine concern for people, care and professionalism. However, human resource is the main driver of innovation diffusion [4].

Universities connections to the labor market are not a simple process, nor a strategic action. Of course, structural changes in Romanian society, the constant social, economic fluctuations from different areas of activity, and sometimes oscillating relative performance of industrial space, could not provide the guide for university to follow employers requirements. However, higher education should not always generate the skills and professional qualifications as required by labor market disrupted by various temporary factors.

Human resource development and quality assurance in higher education system, covers two categories:

a) Graduates - by providing the skills, abilities and skills enabling easy insertion into the labor market in line with its requirements;

b) Academic staff - in the spirit of the formation and development of initial and continuing modernization.

For universities, human resource development is regarded as advantageous in conditions which ensure [1]:

- Develop educational programs directly related to the dynamic requirements of the labor market for graduates with skills training, skills and abilities required by employers and meeting the needs of a globalized market;

- Develop educational programs to generate superior skills of their graduates as key factors to stimulate creativity, innovation, entrepreneurship, leadership;

- Developing the skills of the existing workforce currently employed;

- Improving education and increase the visibility of universities;

- Develop students' aspirations.

\subsection{Quality Assurance in Public Higher Education System}

Quality is a concept that receives various meanings, but we can agree that the quality is the fulfillment of human resources quality. Any modern organization should be able to use all the tools necessary to identify human resources potential and their ways of development in terms of performance. From this perspective, the implementation of a quality management system is a very important activity in today's human resource management.

Quality assurance and accreditation in higher education is defined as systematic management and assessment of procedures adopted by higher education institution or system to monitor performance and to ensure achievement of quality improvement. Quality assurance aims to give stakeholders confidence about the management of quality and the outcome achieved. The provision for education is mainly the responsibility of the government, which is interested in educational quality assessment because [6]:

- has constitutional obligation to assure quality of education

- accountability in use of public resources is to be assured and

- provision of quality education for all the eligible aspirants is a political decision, which enjoys a strong social support. It is imperative therefore to identify the characteristics of quality, evolve strategies for fostering it, identify the factors affecting it, examine the relationship between quality and resources, and explore the measures of monitoring changes over time. To do this, a common framework is needed for gathering qualitative and quantitative data and for analyzing them, to assess quality and to assure the stakeholders of their quality.

Attention to quality assessment in higher education has increased in recent decades. Various international authors, especially in the U.S., UK and Australia, highlights the importance of teaching evaluations and marks the main poles of the teaching assessment: teaching, learning in its various forms, performance, skills.

Quality of educational services offered in the academic environment depends largely on the quality of human resources, in the quality of teachers. The minimum requirements necessary to ensure the quality of teachers are given the laws of the Romanian state, designed to motivate and encourage the maintenance of the professional qualities and manage it intelligently and efficiently returns [3].

Since the role of higher education is the training of future specialists, a requirement to fulfill this mission is providing highly qualified human resources. This involves a multitude of particular aspects: an efficient selection process, adequate reasons to support continuing professional development, a performance appraisal that truly represents a step in the optimization of teachers, a proper reward efforts and professional success compliance with the psychological contract.

\subsection{Performance Evaluation of Human Resources in Public Higher Education System}

Higher education institutions in our country must be prepared to operate in a competitive education market, assuming greater managerial autonomy for each of them, a flexible regulatory framework and adequate financing. Today, being competitive as an institution of higher education requires more openness and transparency, a review of services and marketing culture, according to the European realities and values of the European education system, such as cultural diversity and research orientation. 
The evaluation of professional performances is the main activity of the human resources management to determine the extent at which the employees perform their tasks efficiently and the responsibilities which have been assigned to them.

The performances evaluation is an activity through which employees" motivation takes place, it maintains the personal contacts, recognizes the quality work and promotes a certain image on those issues that are evaluated. The knowledge of performances provides the evaluated with confidence in their own powers, as well as they constitute a mobilizing factor or a generating factor of positive attitude towards work.

The relevance of human resource is growing exponentially in an academic institution where the affirmation and development engine relies on the innovation at the spiritual and material level, where the opening of new fields of investigation, approaching of newly emerging phenomena and processes, formulating theories and hypotheses, measures and solutions for the needs of the immediate practice become the sine qua non conditions of the worthiness and of the performance. The performances evaluation of the members of the academic community is a part of the continuous improvement process of these in accordance with the valid legislation. According to the usual formulation, the performance and the success of the faculty are represented by the totality of the results and the behaviors on the strength of which the contribution of individuals and groups is assessed.

Regarding the human performances, the following paragraphs show both the instances of HR as external factors and as internal factors. The internal factors influence through feedback positively or negatively on the external factors. The performance actions also influence, through feedback both internal factors and external ones. The internal factors are manifested as a dynamic factor of the performance and can influence it positively or negatively. These factors may be one or more of the following: informational, psychological, educational, genetic, training or biorhythm.

The external factors, of informational-instructional and educational nature, are located in the school and in the family, and those technical, organizational and psychosocial natures are located in the public institutions and the market economy. If the action of the external factors is the brake, they become the obstacles to the performance. The quality of the national education, its power to create the future creators, is the main factor that prefigures the future position of a nation in the world. For these reasons, the cultivation of individual and group creativity in the education generally and in the higher education in particular is the major imperative of the education.

The interdependence between the factors of influence and human performance is shown in Figure below.

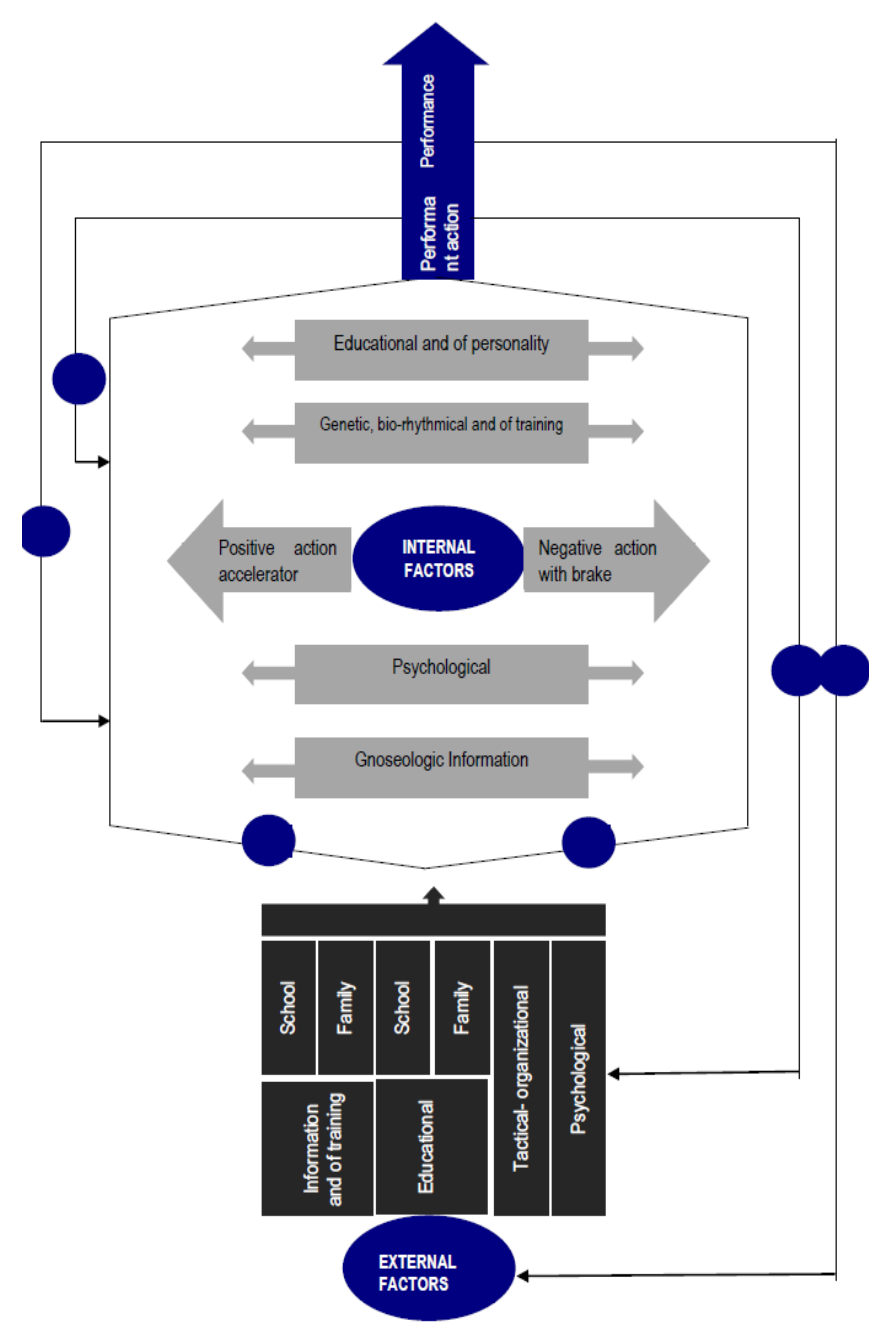

Figure. The performance factors

In the context of human resource development in universities proposed approach evaluation indicators at three levels [2]:

a) Indicators for assessing the quality of university management;

b) Indicators for assessing the quality of teaching;

c) Indicators for assessing the quality of results.

The main objectives that a university must have through the complex process of evaluating the performance of employees must:

- $\quad$ identify professional development needs of teachers and to evaluate the results of previous programs;

- employees aware of the link between their performance and the performance of the university;

- $\quad$ promote key attitudes and behaviors of individual stations;

- evaluate individual and team goals (department, faculty);

- to act as a support for effective communication;

- to increase the employee's motivation;

- $\quad$ to be the starting point for developing career teachers. The evaluation system is applied in the following cases [7]:

- the regularly evaluation of the quality of teaching and 
research staff as part of the evaluation system of quality and assurance of the education quality . Each teacher will be evaluated at least every five years;

- the evaluation to fill trough the competition a teaching position;

- $\quad$ the evaluation for acquiring the quality of Doctorate Head;

- the evaluation to obtain the gradations and the wage incentives.

To assess the quality of teaching and research staff, there are called to the following criteria:

- Criterion 1: Teaching Activity;

- Criterion 2: Research Activity;

- Criterion 3: Scientific Contribution

- Criterion 4: Professional Prestige

Teaching Activity is reflected in a report summarizing the activity which is done in the last academic year, which includes the information and the assessments from the following sources:

- the evaluation from the students;

- the evaluation from the colleagues;

- the evaluation from the department director;

- the self-evaluation of the teaching activity.

The evaluation from the students receives three categories of persons: the teachers who use the students" evaluations to get feedback on teaching to improve the courses and the teaching methods, the students who use the evaluation information to make an effective choice of the courses and the leadership which can use this comparative information within the human resources management.

The questionnaires which are for the students can be used to assess the teaching activities in general, of courses, seminars and other applicative activities, or to assess the studies programs of Bachelor, Master and $\mathrm{PhD}$.

\section{Conclusions}

Human resource development in terms of extending the knowledge economy takes place in a competitive environment defined by the criteria of efficiency, economic performance and competitiveness. All these require investment in human resource priority to create industry-specific professional skills and ability to adapt to dynamic labor market requirements, anticipatory connecting higher education to the labor market represents a sine qua non of human resource development in terms of achieving performance organizational.

In conclusion, after studying the problem of professional performances evaluation in romanian higher education institutions we can say that:

- the students evaluation is based upon the premise that this is the most important group of clients and beneficiaries of the academic activity, the university management considering as priority the achievement of requirements and expectations of these concerning the academic training and the activity conditions in the institution;
- the evaluation of the teaching and research staff is a part of development system of the staff, aiming to establish the report between the proposed objectives and those made by the assessed person concerning this person's professional performances, in order to improve these under the teaching, scientific and behavioral aspect;

- the evaluation process intended to ensure the teaching and research staff of highly qualified and professional integrity, which would contributes to increase the efficiency and the educational and research and development activities;

- the key performance constitutes a conscious and responsible involvement of all staff in fulfilling the university mission and goals. On the basis of individual responsibility reinforcing there is a process of continuous training of all the staff which is designed to develop a constructive institutional culture which is geared towards performance and based on the periodic evaluation of progress of the individual performance;

- the professional performance is closely linked to a personal competence and to a human creativity. The performance cannot be achieved without a man to be competent in his field, but it should be noted that only if it is put into action, the competence can lead to the actual performance. As for the creativity, it should not be seen and understood as a necessity only when something have to be innovated, but when there have to be brought a genuine change in an existing situation. The creativity forms the basis of the individual performances;

Nowadays, in order to be considered prestigious universities should be aggressively innovative, proactive and responsive to the needs of different individuals with interest in the field of education. This means that with education and research, an entrepreneurial university should be deeply involved in economic and social development of the region and the country became an agent for promoting the concept of knowledge-based economy.

\section{References}

[1] P. F., Laursen, Authentic teacher. In Beijaard, D., Meijer, P.C., Morine-Dershimer, G., \& Tillema, H. (eds.). Teacher professional development in changing conditions (pag. 199-212). Dordrecht: Springer, Kluwer Academic Publishers, 2005.

[2] A, Manolescu, V, Lefter, A, Deaconu, Managementul resurselor umane, Editura Economică, Bucureşti, 2007, pag. 456.

[3] C. O., Okpala, R., Ellis, The perceptions of college students on teacher quality: A focus on teacher qualifications. Education, 2005, 126.

[4] C., Schifirneț, Studentul, agent al schimbării în câmpul universitar, în Neculau, Adrian. (coord.)Câmpul universitar şi actorii săi, Editura Polirom, Iaşi, 1997, pag. 236. 
46 Muscalu Emanoil et al: The Current State of Quality Management in Human Resources Evaluation Process in Romania Public Higher Education System

[5] G., Schaeffer, K., Epting, T., Zinn, W., Buskit, Student and faculty perceptions of effective teaching: A successful replication. Teaching of Psychology, 30, 2003, 133.

[6] L., Vlăsceanu, A., Miroiu, M., Păunescu, Starea calității în invățământul superior din România, Barometrul calității 2010, Agenția Română de Asigurare a Calității în Învățământul Superior, Bucureşti, 2010.
[7] L., Văcărescu, Hobeanu The human resources and evaluation management in the academic environment, Journal of Advanced Research in Management, http://search.proquest.com/docview/887542397/fulltextPDF /D28B387646294E1APQ/1?accountid=8083. 